\title{
Study on the Sealing and Inactivation Mechanics of Titanium Alloy Tube Flareless Internal Rolling Connection
}

\author{
ZHANG Rong-xia ${ }^{1,2,3, a}$ WU Wei ${ }^{1,2,3, b}$ ZENG Yuan-song ${ }^{1,2,3, c}$ \\ ${ }^{1}$ Beijing Aeronautical Manufacturing Technology Institute \\ ${ }^{2}$ Aeronautical Key Laboratory for Plastic Forming Technologies \\ ${ }^{3}$ Beijing Key Laboratory of digital plasticity forming technology and Equipment \\ azrxia1979@163.com, ${ }^{b}$ wuweifiles@163.com, ${ }^{c}$ zengys@163.com
}

\begin{abstract}
Keywords: titanium alloy tube, flareness internal rolling, sealing mechanics, fretting wear
\end{abstract}
\begin{abstract}
The finite element model of the internal rolling connection process for Titanium alloy tubes was established. The distribution of the elastic strain and the contact force were analyzed to reveal the sealing mechanics of the flareless union. The residual compressive stress was generated between the tube and sleeve, which made the tube and sleeve contact closely. Through the microscopic view analysis of the connection interface between the tube and sleeve before and after vibration test, the vibration fatigue inactivation mechanism was disclosed. In the action of circulate vibration load, fretting wear generated between the tube and sleeve, which broke the original contact state. Then the tube and sleeve can't connect closely and the joint became inactivate.
\end{abstract}

\section{Introduction}

Titanium alloy tube internal rolling connection is a process that makes the tube and sleeve connect together through progressive feeding of the titanium alloy tube wall material into the slotted sleeve. Compared with the flared connection, it has the characteristics of high sealing, self-locking anti-vibration, light weight and long life. The technology is mainly used in the hydraulic pipeline of aircraft engine ${ }^{[1-4]}$.

The titanium alloy tube internal rolling connection technology has completely realized the automatic control of computer, and a connecting tube manufactured by this technology has passed the new Pratt \& Whitney engine installed test. It has already been widely used in 727-767, Airbus aircraft, and gradually extended to the field of aerospace.Russia has developed a special titanium alloy tube rolling connection forming equipment, titanium alloy connecting tube has been widely used in Su-27 and other types of aircraft. China major OEMs have purchased dedicated device from abroad, and gradually applied the technology to new aircraft engines. The pipeline structure parts in flight will be affected by various dynamic loads, such as unsteady aerodynamic force, including turbulence buffeting excitation, boundary layer pressure fluctuation, and the dynamic load generated by abrupt motor power. Therefore, the tube connections must have a certain vibration fatigue performance, to ensure that the tube and sleeve in the service environment is still highly sealed. The research on the tube internal rolling connection technology is carried out in AVIC Beijing Aeronautical Manufacturing Technology Research Institute, and the TA18 titanium alloy tube rolling joint has been tested by 28MPa system working pressure verification test. In the aspect of theoretical research. Zeng Yuansong made a comparative analysis on the forming effect of the rectangular groove and triangular groove sleeve, and pointed out that the triangular groove has larger contact surface than the rectangular groove, and the connection effect is good ${ }^{[1]}$. Lv Xinyu studied the effect of different groove width on forming, and pointed out that the larger groove width is more conducive to sealing ${ }^{[2]}$.They are mainly from the perspective of the contact surface to analyse the sealing mechanism. The external diameter of the rolling joint sealing performance is also reported. There are also few reports on the sealing performance of the inner diameter of the roll connection joint abroad. The research on fatigue failure of joints is still blank in China, which has become a bottleneck in the application of this 
technology in aircraft engines. In this paper, the finite element analysis method is used to grasp the sealing mechanism of tube internal rolling connection. The fatigue failure mechanism of the joint is revealed from the micro interface of the connector.

\section{Introduction to technical principles}

The inner diameter rolling deformation belongs to local cyclic loading deformation. The basic principle of its forming is to press the titanium alloy tube wall material into the grooved sleeve by the radial force applied by the circumferential rolling, so that the tube and the sleeve implement the connection. At the beginning of the connection, the mandrel rotates and drives roller rotating along the inner wall of the tube. The cage is driven by the roller, and the mandrel is continuously fed in the axial direction to feed the roller radially, so as to achieve the tube rolling extrusion. Thus, the tube and sleeve are connected by plastic deformation.

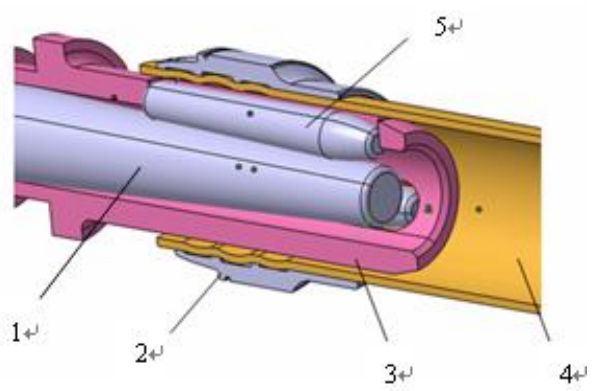

Fig .1 The principle of the internal rolling process (1- mandrel,2-sleeve,3-shell of expander,4- tube ,5-rollers)

\section{Analysis of sealing mechanism of tube and sleeve}

Establishment of finite model for connection process. Hypothesis and simplification is shown below.

$\mathrm{n}$ Make the following assumptions when simulating:

$\mathrm{n}$ Material is isotropic;

Because of the high-speed rotation of three rollers in the forming process. The time when the tube is not stressed is very short, so the roller is seen as a continuous contact with the tube ${ }^{[5-7]}$.

At the same time, regarding the connection process as axisymmetric problem, it can be simplified to two dimensions, and intercept a longitudinal plane to simulate.

Material model.The tube material is TA18, the specification is $\Phi 8 \times 0.75$; the sleeve material is 69111. The material parameters are shown in Table 1. The material model is an elastoplastic model, which is discretized into an axisymmetric solid element, and the Von Mises yield criterion is used.

Table 1. The parameters of the material

\begin{tabular}{cccccc}
\hline Material name & $\begin{array}{c}\text { Elastic } \\
\text { Modulus } \\
{[\mathrm{GPa}]}\end{array}$ & $\begin{array}{c}\text { Poisson's } \\
\text { ratio }\end{array}$ & $\begin{array}{c}\text { Yield } \\
\text { Strength } \\
{[\mathrm{MPa}]}\end{array}$ & $\begin{array}{c}\text { Tensile } \\
\text { strength } \\
{[\mathrm{MPa}]}\end{array}$ & Elongation \\
\hline TA18 & 96 & 0.3 & 570 & 757 & $15 \%$ \\
69111 & 206 & 0.34 & 1330 & 1660 & $13.7 \%$ \\
\hline
\end{tabular}

Constraint loading. The four steps of the forming process are contact between the roller and the inner wall of tube, connection forming, unloading and springback. When calculating the springback, the contact constraint between the tube and sleeve is canceledand both are free to springback. The radial load is applied to the roller, and the loading curve is shown in Figure 2. The time $0-3 \mathrm{~s}$ is the whole forming stage, and the $3 \mathrm{~s}-4 \mathrm{~s}$ is the springback stage. The constraints of tooling on the sleeve are simplified as the displacement constraints of the tube sleeve profile.

The tangential contact of each component is based on the penalty function friction formulain which friction coefficient is 0.1 , and the normal contact is set as hard contact. 


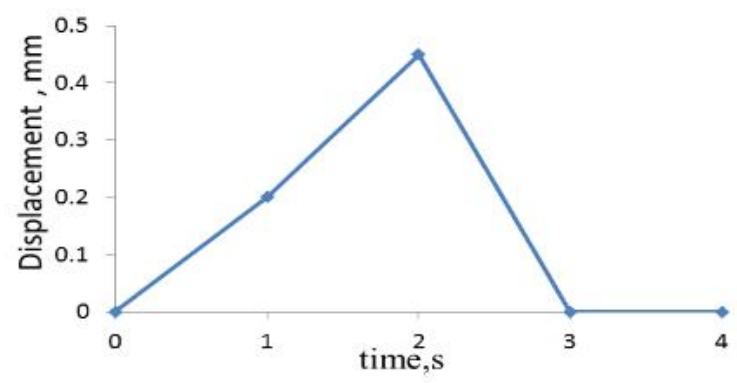

Fig. 2 The displacement load of the roller

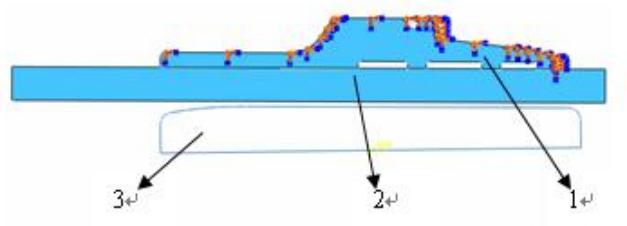

Fig. 3 The finite element model of the connection process

(1-sleeve, 2-tube, 3-rollers)

Sealing mechanism analysis. Figure 4 shows the elastic strain distribution before and after springback of the connection forming. The tube and sleeve are elastically deformed in connection forming. After unloading, the tube and sleeve have bigger springback, the change of tensile strain is small while the change of compressive strain is large. The maximum compressive strain of the sleeve decreases from $8.034 \mathrm{e}-03$ to $5.99 \mathrm{e}-03$, which is $25 \%$ lower. And the maximum compressive strain of the tube decreases from $2.379 \mathrm{e}-02$ to $1.709 \mathrm{e}-02$, which is $28 \%$ lower. The contact direction of the two parts is opposite, and the overlapping area is formed after the springback, so that the tube and sleeve are closely connected before the springback. Figure 5 shows the contact force curve changes with time. With the roller feed, the contact force increases gradually. The contact force gradually decreases in the process of unloading. At the end, the residual contact force between the tube and sleeve is still exist (about $61.3 \mathrm{~N}$ ), and the residual contact force is the key factor to ensure sealing of the tube and sleeve. The greater the residual contact force, the better the sealing ${ }^{[8]}$.

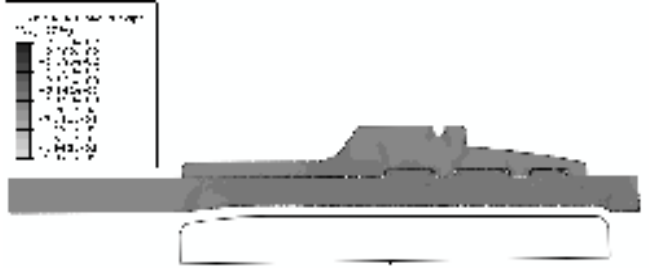

Before spring back

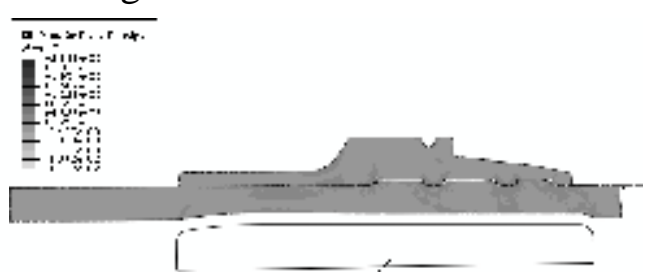

After spring back

Fig .4 The equivalent elastic strain distribution of tube and sleeve

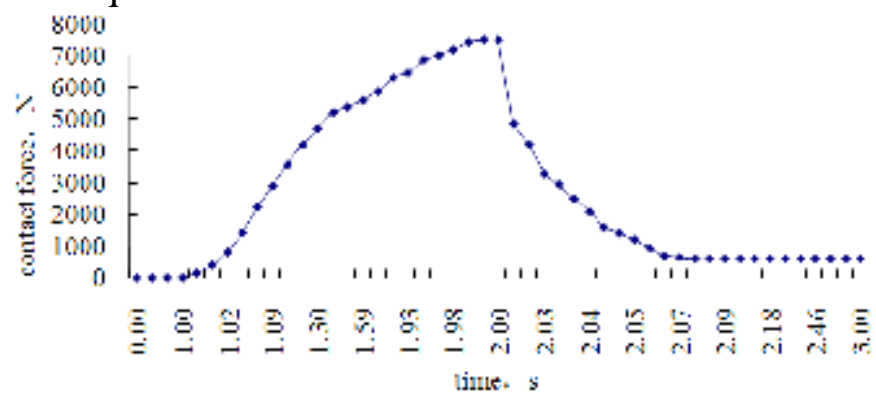

Fig .5 The curve of the contact force in the forming process

\section{Failure mechanism analysis of tube and sleeve connection joint}

Vibration fatigue test of titanium alloy tube internal rolling connection.Refer to HB5277-84 "Test method for vibration and fatigue of engine blades and materials" ${ }^{[9]}$. A TA18 $\Phi 8 \times 0.75$ typical 
titanium alloy tube internal rolling connection (sleeve material is 69111) was tested to determine the fatigue limit strength.

The structure of the tube vibration fatigue test piece is shown in figure 6. According to the theoretical analysis results, two strain gauges were installed at the maximum stress point, and the strain gauges were symmetrically distributed. In the test, the titanium alloy pipe was placed horizontally and fixed on the vertical table of the shaking table. The installation method is shown in figure 6. Using a fixed frequency excitation test pieces, In order to pass the test, it is required that the number of vibration cycles must reach $2 \times 10^{7}$ at the stress level. The vibration amplitude of the strain gauge is monitored at the stress level. When the excitation frequency is reduced by $1 \mathrm{~Hz}$ compared with the initial state, and the amplitude can not remain stable, the test piece will be invalid.

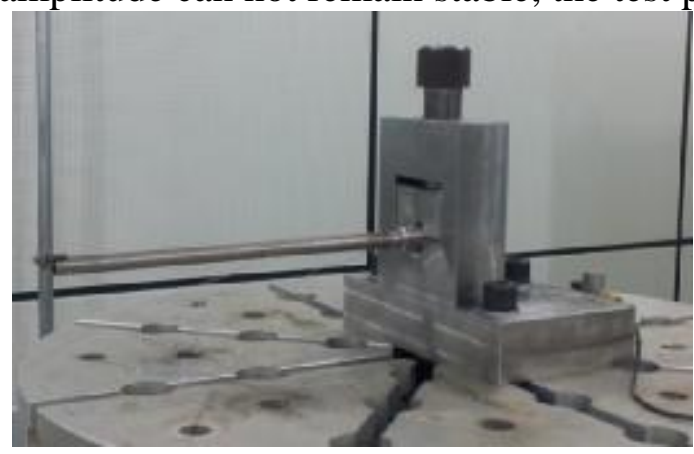

Fig. 6 Installation of test piece

Mechanism analysis of vibration fatigue failure.Microscopic observation of test pieces without vibration and vibration failure was carried out, respectively. The 1/2 and 1/4 of the sleeve and the tube joint were taken out by wire cutting, in which the upper part of the sleeve and the tube joint was mainly observed in the $1 / 2$ part to observe whether or not the gap occurred due to vibration fatigue. Intercepting the 1/4 part was to separate the sleeves and the tube. The surface morphology of the contact surface of the sleeve and the tube was observed in order to see whether there were wear marks and wear debris. Figure 8 shows the schematic diagram of the analysis part.

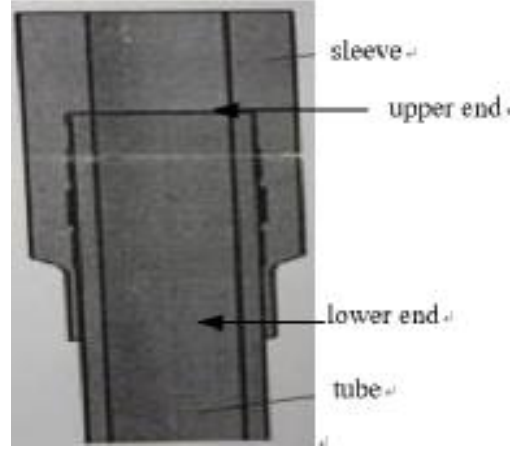

Fig. 7 schematic diagram of analysis part

Figure 8 (a) shows the upper end of the tube and the sleeve joint without the vibration of the specimen, where the point of arrow in the picture is closely connected with no gaps. Figure 9 (c) shows the enlarged shape of the inner surface of the sleeve, and the machining marks can be seen obviously. Figure 9 (d) shows the surface morphology of the tube in the $1 / 4$ part.

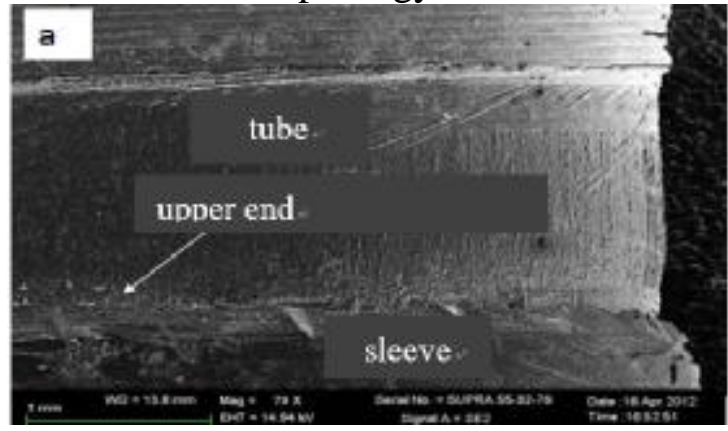




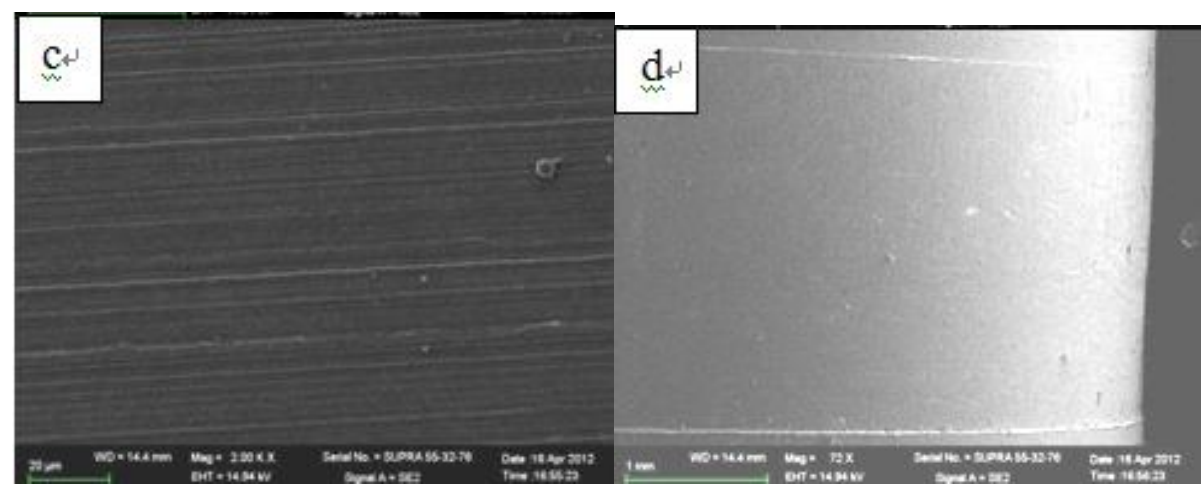

Fig. 8 Specimens without vibration fatigue test

Figure 9 (a) shows the upper end of the contact of the vibrating failure specimen tube and sleeve. It can be seen that there is a gap at the joint under the vibration load (about $0.25 \mathrm{~mm}$ ). Figure 9 (b) and 9 (d) show the lower end of the tube and sleeve contacts, respectively. It can be observed that there are obvious wear marks, and the wear marks are scattered, indicating the contact part of the local wear and tear occurred. Figure 9 (c) is an enlarged view of the wear area of Figure 9 (b). Figure 9 (e) is an enlarged view of the wear region of Figure 9 (d). It can be seen that the cover and the surface of the tube and sleeve have been destroyed and the material is accumulated. However, the displacement of the material at the wear site is small, which can be considered as fretting wear. Fretting wear is a kind of special wear mode caused by periodic small amplitude vibrations on the two solid contact surfaces. It occurs in a relatively stationary working contact surface. The small relative displacement is caused by the vibration of the environment or one of the contact components suffered alternating stress under the action of a certain normal load between the surfaces that are in contact with each other ${ }^{[10-15]}$. Judging from the microscopic morphology, between the tube and the sleeve should be adhesive wear, the material transfer between them. Figure 9(f) is the analysis of the composition of the Red Cross wear debris in Figure 9 (e), the content of the Fe element reaches 77\%, which can be used to determine the material transfer to the tube.
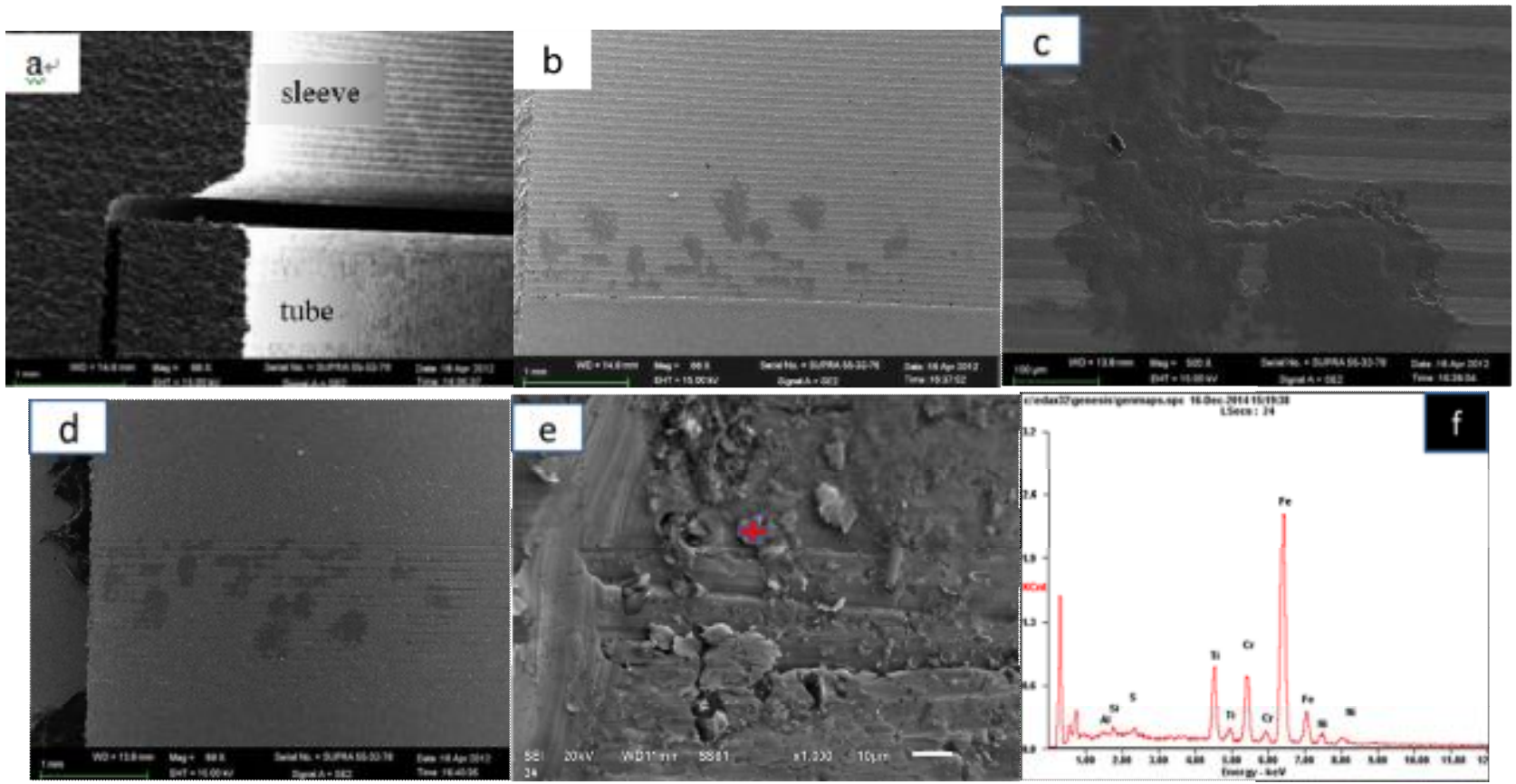

(a) The connection of the post-vibration tube to the sleeve(b) Distribution of sleeve wears area

(c) Enlarged view of sleeve wears area (d) Distribution of tube wears area

(e) Enlarged view of tube wears area (f) analysis of abrasive composition in tube wear area

Fig.9 surface morphology of contact surface of the connector

From the above analysis, it can be concluded that the vibration fatigue failure mechanism of the titanium alloy tube internal rolling connection is: under the cyclic vibration load, the micro-wear occurs between the tube and the sleeve contact surface, and the original contact condition is damaged. 
When the abrasion is accumulated to a certain extent, the contact between the tube and the sleeve is not strong enough, the connector failure.

\section{Conclusions}

(1)The sealing mechanism of the titanium alloy tube inner diameter rolling joint is that the elastic deformation of the tube and the sleeve is existed, and the elastic recovery direction of both contacts is opposite, so that the two closely connected together.

(2) The vibration fatigue failure mechanism of the titanium alloy tube internal rolling connection is: under the cyclic vibration load, the micro-wear occurs between the tube and the sleeve contact surface, and the original contact condition is damaged. When the abrasion is accumulated to a certain extent, the contact between the tube and the sleeve is not strong enough, the connector failure.

(3) For engineering application, the research of titanium alloy tube internal rolling connection technology should focus on the joint failure analysis of the influencing factors, and how to improve the fretting wear failure and fatigue resistance, to meet high reliability demand of aircraft engine hydraulic pipeline.

\section{References}

[1] Zeng Yuan-song. Finite element simulation and experimental research on the internal rolling connection for titanium alloy tubes . Materials Science Forum , Vols. 475-479(2005)pp. 3287-3200.

[2] LV Xin-yu,ZHANG Shi-hong, ZENG Yuan-song. Models of FEM simulation on roller inner swaging of connecting tubes and analysis ,JOURNAL OF PIASTICITY ENGINEERING,2005,12(3):85-88.

[3] ZHANG Rong-xia, WU Wei, ZENG Yuan-song,ect. The study on the sealing capability of the flareless internal rolling union, OURNAL OF PIASTICITY ENGINEERING,2011,18(3):75-79.

[4] ZHANG Rong-xia WU Wei ZENG Yuan-song. The three-dimensional finite element analysis on the internal rolling connection, JOURNAL OF PIASTICITY ENGINEERING,2011,18(4):85-89

[5] YIN Zi-wu. The Kinematics Analysis of the Three Planet Rollers Mill for Helical Gill Tube. METAL FORMING TECHNOLOGY,2001,19(2):18-20

[6] LI Bing, YANG Zhi, ZHANG Shi-hong. Computer simulation on the movement and deformation rules of three-roll planetary rolling process of Copper tube, JOURNAL OF PIASTICITY ENGINEERING,2005,12(5):70-73

[7] ZHANG Xin-wang, WANG Yong, WU Xiao-wei. Numerical simulation of three-roll screw rolling process for titanium alloy bar, ROLLING \& STAMPING TECHNOLOGY.,2011,36(1):61-64.

[8] Duan Cheng-hong. STUDY OF THESTRENGTH AND TIGHTNESS OF TUBE TO TUBE SHEET CONNECTIONJOINTS [D]. Beijing: Beijing University of Chemical Technology, 2007.

[9] HB5277-84 《Test method for vibration and fatigue of engine blades and materials》

[10]Xia Wei, Li Feng-lei ,Tang Zheng-qiang, Zhou Zhao-yao ,Zhao Jing. Influence of Burnishing on Fretting Wear Behaviors of Aluminum Alloy 6061. Journal of South China University of Technology（Natural Science Edition)），2011，39（1）: 84 89. 
[11]Zhang Xiao-hua, Liu Dao-xin, Liu Guo-hua, Wang Zhen-ya, Tang Bin. Effects of Cu/Ni Multilayer Film on Fretting Wear and Fretting Fatigue Resistance of Ti811.Alloys RARE METAL MATERIALS AND ENGINEERING, 2011，40（2）: 294 300.

[12] Shiou F J , Chuang C H.Precision surface finish of the mold steel PDS5 using an innovative ball burnishing tool embedded with a load cell[J].Precision Engineering, 2010, 34 (1) : 76 84.

[13]LIU Dao-xin, HE Jia-wen. REVIEW OF FACTORS THAT INFLUENCE FRETTING FATIGUE ( FF) AND INVESTIGATION ON FF BEHAVIOR OF Ti-ALLOY. ACTA AERONAUTICA ET AST RONAUTICA SINICA, 2001,22（5）: 454 457.

[14]LIU Dao-xin, HE Jia-wen. Comparative Study on the Fretting Fatigue and Fretting Wear Behaviors of Titanium Alloy Subj ect to Various Surface Modifications. TRIBOLOGY, 2005,25 (1) : 13 17.

[15] JIN Fan-ya, TONG Hong-hui , SHEN Li-ru. Micro-structural and dielectric properties of porous $\mathrm{TiO} 2$ films synthesized on titanium alloys by micro-arc discharge oxidization [ J]. Materials Chemistry and Physics, 2006, 100: 31 33. 